\title{
Pengendalian Tracking Posisi Purwarupa Autonomous Land Vehicle dengan Menggunakan Metode Pid dan Model Kinematik
}

\author{
Swadexi Istiqphara, Rudi Uswarman, Heriansyah, Anggi Mukti Utama \\ Program Studi Teknik Elektro, Institut Teknologi Sumatera \\ Lampung, Indonesia \\ swadexi.istiqphara@el.itera.ac.id
}

\begin{abstract}
Intisari - Teknologi sistem autonomous saat ini mulai banyak dikembangkan untuk berbagai aplikasi seperti industri dan transportasi umum. Berbagai metode telah banyak dikembangkan untuk mengendalikan suatu wahana secara otomatis baik dengan kombinasi sistem kendali cerdas (AI) atau dengan metode kendali nonlinear. Salah satu kendala dalam kendali autonomous ini adalah akurasi GPS yang kurang akurat. Dalam jurnal ini, akan implementasi metode kontrol berbasis model kinematik wahana untuk memperbaiki akurasi GPS, sehingga akan meminimalisir terjadinya tabrakan atau lintas jalur. Wahana yang digunakan berupa purwarupa mobil mainan bertenaga baterai yang dimodifikasi agar dapat dikendalikan secara autonomous, dimana wahana ini bernavigasi menggunakan sistem steering pada dua roda depan. Pengujian akan dilakukan pada area jalan ITERA, dimana wahana akan diberikan lintasan yang diberikan melalui perangkat lunak komputer dan dipantau secara nirkabel. Sumber daya wahana diperoleh dengan dua cara yaitu dengan menggunakan sumber listrik dari panel surya dan dari baterai.
\end{abstract}

Kata kunci — Autonomous car, Land Vehicle, Filter GPS, Model Kinematik, Electric Vehicle

Abstract - Autonomous system technology is currently being developed for various applications such as industry and public transportation. Various methods have been developed to control a vehicle automatically either by a combination of intelligent control systems (AI) or with nonlinear control methods. One obstacle in autonomous control is GPS accuracy that is less accurate. In this journal, a kinematic model-based control method will be implemented to improve GPS accuracy, so as to minimize collisions or cross lanes. The vehicle used in the form of a prototype battery-powered toy car that was modified to be controlled autonomously, where this vehicle navigated using the steering system on the two front wheels. The test will be carried out on the ITERA road area, where the vehicle will be given a path provided through computer software and monitored wirelessly. Vehicle resources are obtained in two ways, namely by using electricity from solar panels and from battery.

Keywords - Autonomous car, Land Vehicle, Filter GPS, Model Kinematik, Electric Vehicle Prototype 


\section{PENDAHULUAN}

Saat ini teknologi wahana tak berawak telah banyak digunakan dalam keperluan seperti pengawasan, pencarian dan penyelamatan. Secara umum, wahana tak berawak dapat digolongkan kedalam tiga jenis, wahana udara, wahana laut tak berawak dan wahana darat. Fokus penelitian ini adalah wahana darat tak berawak yang bergerak secara otomatis(Autonomous Land Vehicle / ALV), wahana darat berawak kedepannya akan memiliki beberapa aplikasi penggunaanya, beberapa diantaranya adalah :

1. Bidang transportasi, sebagai contoh bus, mobil pribadi dan sepeda

2. Wahana dengan fungsi sebagai contoh yaitu truk sampah otomatis, robot industri

3. Wahana pertanian, sebagai contoh traktor, pemotong padi dan penanam padi.

Seiring dengan pesatnya teknologi, wahana darat tak berawak mulai dikembangkan untuk dapat bergerak secara otomatis (autonomous) sehingga operator hanya perlu memberikan target lintasan yang harus dilewati dan aksi yang harus dilakukan oleh wahana. Beberapa penelitian telah dilakukan untuk dapat membuat wahana darat tak berawak dapat bergerak secara autonomous, diantaranya adalah dengan menggunakan kecerdasan buatan pada computer vision untuk dapat melihat jalan dan halangan di sekitar wahana, selain itu wahana juga dilengkapi dengan sensor Global Positioning System (GPS). GPS yang dapat digunakan untuk umum memiliki kelemahan yaitu tingkat kesalahan posisi pada bidang horizontal sebesar $\pm 2 \mathrm{~m}$, nilai kesalahan ini cukup besar untuk wahana dapat bernavigasi dengan baik secara autonomous.Penelitian ini akan menerapakan persamaan model kinematika wahana darat untuk memperbaiki kesalahan informasi GPS agar memiliki kesalahan mendekati nol, untuk melakukan tracking posisi, digunakan metoda kontrol Proportional Integral dan Derivative (PID.

\section{DASAR TEORI}

Metode kontrol Proportional, Integral dan Derivative (PID) adalah metode kontrol yang paling banyak digunakan dalam dunia industri[1], hal ini dikarenakan metode PID ini dapat digunakan dengan mudah dan memiliki proses komputasi yang ringan, sehingga hampir semua perangkat sistem kendali seperti microcontroller dan komputer dapat menggunakan metode PID ini, selain itu metode PID juga memiliki kemampuan untuk membuat sistem menjadi lebih robust terhadap gangguan, hal ini dikarenakan terdapat kontroler Integrator pada metode PID. Persamaan PID, dinyatakan dengan persamaan berikut [2]:

$$
\begin{aligned}
& u_{p}=K_{p} * e \\
& u_{d}=K_{d} \frac{d e}{d t} \\
& u_{i}=K_{i} \int e d t \\
& u_{p i d}=u_{p}+u_{i}+u_{d}
\end{aligned}
$$

Dimana $\mathrm{Kp}$ adalah gain atau konstanta proportional, Ki adalah konstanta integral dan Kd adalah konstanta Derivative. GPS adalah jaringan satelit yang terdiri dari sekitar 24 satelit yang mengelilingi bumi sebanyak dua kali sehari pada ketinggian 11.000 mil. Seperti yang ditunjukan pada Gambar 1.

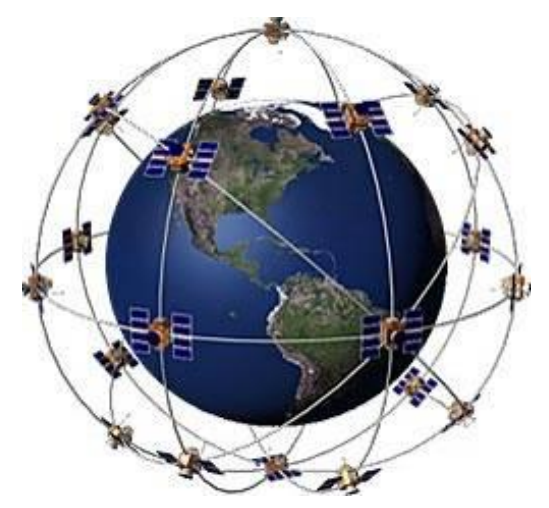

Gbr.1 Satelit yang Melintasi Bumi 
Pada awalnya, GPS dikembangkan oleh United States Department of Defense (DOD) untuk kepentingan militer. Setelah beberapa tahun berlalu, GPS telah terbukti efektif dalam menentukan posisi, sehingga mulai digunakan oleh umum seperti saat ini.

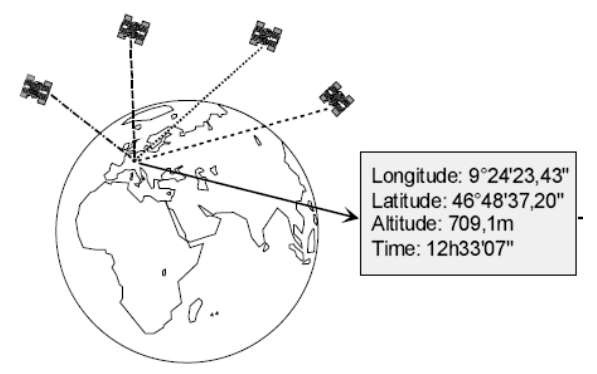

Gbr.2 Pembacaan posisi pada bumi menggunakan GPS

Setiap satelit GPS mengirimkan dua sinyal, PPS (Precise Positioning System) dan SPS (Standar Positioning System). Sinyal PPS dienskripsi dengan kode akses militer, sedangkan SPS tidak dienskripsi. Pengrirman kode informasi menggunakan gelombang mikro dengan frekuensi 1575,42 MHz.[3] Tidak seperti sinyal yang berasal dari bumi, sinyal SPS lebih tahan dari interferensi waktu malam, dan tidak dipengaruhi oleh cuaca dan noise elektris. Sinyal SPS terdiri dari dua tipe data orbit, almanac, dan epheremis. Data almanac berisi kekuatan sinyal dan perkiraan lokasi dari setiap satelit pada sistem. Penerima GPS mengumpulkan data almanac dari satelit yang ada, yang kemudian menggunakannya untuk menentukan lokasi satelit yang seharusnya dapat dilihat dari lokasi penerima. Pada Gambar 2 dapat dilihat satelit mengirimkan data ke GPS receiver. Data ephemeris berisi orbit parameter yang tepat dari satelit yang bersangkutan. Penerima GPS menerima sinyal dari tiga atau empat satelit pada saat yang sama dan menentukan posisi fix dengan menggunakan interval antara pengiriman dan penerimaan dari sinyal satelit. Tiga satelit dibutuhkan untuk posisi dua dimensi.
Posisi dua dimensi hanya menunjukkan posisi. Empat satelit dibutuhkan untuk posisi tiga dimensi, yang menunjukkan posisi dan elevasi. [4]

Untuk memperoleh variabel seperti posisi, kecepatan, dan lainnya, modul GPS memiliki antarmuka serial (TTL atau level RS-232). Elemen paling penting dari informasi penerima dikirim melalui antarmuka ini dalam format data khusus. Format ini distandarisasikan oleh NMEA (National Marine Electronics Association) untuk meyakinkan jika ada perubahan data tidak menimbulkan suatu masalah. NMEA telah menetukan tipe data untuk bermacam-macam aplikasi, contohnya GNSS (Global Navigation Satellite System), GPS, Loran, Omega, Transit, dan juga untuk beberapa manufaktur [5].

\section{PERSAMAAN MATEMATIKA}

Langkah awal dalam menentukan sistem kendali dalam penelitian ini adalah dengan melakukan pemodelan wahana. Pemodelan ini bertujuan untuk mendapatkan persamaan matematika dari wahana, dimana persamaan matematika wahana ini akan digunakan untuk memperbaiki kesalahan informasi yang diberikan GPS. Wahana yang digunakan merupakan purwarupa mobil mainan anak seperti yang ditunjukan pada gambar 3 . Wahana ini memiliki sistem navigasi steering, dimana untuk melakukan belokan dua buah roda depan akan membentuk sudut. Untuk melakukan tracking posisi koordinat $\mathrm{x}, \mathrm{y}$ terdapat dua variabel yang harus dikendalikan yaitu arah heading(steering) wahana dan kecepatan perpindahan wahana. Sistem kendali pengendalian steering wahana menggunakan metode kontrol proporsional. Motor yang digunakan untuk memutar steering adalah motor dc, sehingga digunakan potensiometer untuk mendeteksi perubahan sudut wahana. 

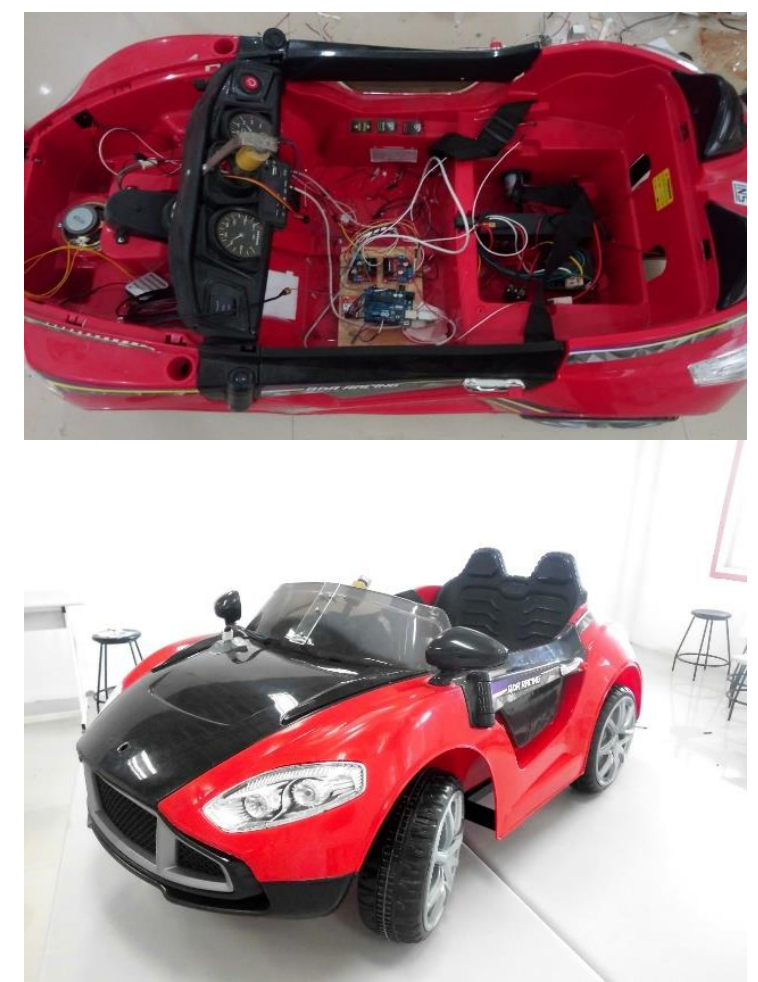

Gbr.3 Wahana Darat dari Mobil anak yang dimodifikasi

Metode kontrol yang digunakan untuk melakukan tracking posisi adalah metoda PID yang dinyatakan sebagai berikut :

$u_{p w m}=K_{p} \cdot e+K_{i} \cdot \int e d t+K_{d} \cdot \dot{e}$

1)

Dimana $\mathrm{Kp}=$ Konstanta proporsional

$\mathrm{Ki}=$ konstanta Integral

$\mathrm{Kd}=$ konstanta Derivative

e $=$ target_posisi - posisi_aktual

$\mathrm{u}=$ besarnya pwm kecepatan roda

dengan e $=$ Target (latitude, longitude $)-$ Posisi Aktual (latitude, longitude) dimana posisi latitude adalah koordinat bumi yang membentang dari kutub selatan hingga kutub utara. Sedangkan longitude adalah koordinat bumi yang membentang dari Bujur timur hingga bujur barat.

Koordinat bumi keluaran GPS akan dinyatakan sebagai berikut :

$$
\begin{aligned}
& x_{g}=\text { longitude } \\
& y_{g}=\text { latitude }
\end{aligned}
$$

Untuk melakukan konversi koordinat body ke koordinat bumi dengan cara menggunakan persamaan berikut :

$x_{g}=x+a \cos \theta$

$y_{g}=y+a \sin \theta$

Dengan menurunkan persamaan diatas maka diperoleh :

$$
\begin{aligned}
& \dot{\mathrm{x}} g=\dot{\mathrm{x}}-a \dot{\theta} \sin \theta=u \cos \theta-a \dot{\theta} \sin \theta \\
& \dot{\mathrm{y}}_{g}=\dot{\mathrm{y}}+a \dot{\theta} \sin \theta=u \sin \theta+a \dot{\theta} \cos \theta
\end{aligned}
$$

Kemudian Kuadratkan nilai ẋg dan ýg dari persamaan diatas yang dinyatakan dengan

$$
\begin{aligned}
\dot{x} g^{2}+\dot{y} g^{2}= & (u \cos \theta-a \dot{\theta} \sin \theta)^{2}+(u \sin \theta+a \dot{\theta} \cos \theta)^{2} \\
& =u^{2} \cos ^{2} \theta+a^{2} \dot{\theta}^{2} \sin ^{2} \theta- \\
& 2 u a \dot{\theta} \cos \theta \sin \theta+u^{2} \sin ^{2} \theta+ \\
& a^{2} \dot{\theta}^{2} \cos ^{2} \theta+2 u a \dot{\theta} \cos \theta \sin \theta \\
& =u^{2}+a^{2} \dot{\theta}
\end{aligned}
$$

Dari persamaan diatas maka nilai $\theta^{*}$ dapat diperoleh yaitu :

$\dot{\theta}= \pm \frac{1}{a} \sqrt{x_{g}^{\dot{2}}+\dot{y}_{g}^{2}-u^{2}}$

Arah orientasi dan posisi wahana dapat diperoleh dengan cara rekursif menggunakan rumus pada Persamaan berikut ini

$\theta[n]=\theta[n-1] \pm$

$\frac{\Delta T}{a} \sqrt{\left(\frac{x_{g}[n]-x_{g}[n-1]^{2}}{\Delta T}\right)+\left(\frac{y_{g}[n]-y_{g}\left[n-1^{2}\right]}{\Delta T}\right)^{2}-u^{2}}$

$x[n]=x[n-1]+u \Delta T \cos (\theta[n])$

$y[n]=y[n-1]+u \Delta T \sin (\theta[n])$

Persamaan diatas digunakan saat diperolehnya nilai posisi baru yang diberikan oleh GPS, untuk dapat mengkombinasikan posisi dari GPS maka digunakan formulasi berikut ini :

$$
\begin{aligned}
& \theta[n]=\operatorname{atan}\left(\frac{y_{g}[n]-y[n-1]}{x_{g}[n]-x[n-1]}\right) \\
& x[n]=x_{g}[n]-a \cos (\theta[n]) \\
& y[n]=y_{g}[n]-a \sin (\theta[n])
\end{aligned}
$$


Diagram Sistem Autonomous Land Vehicle (ALV) pada penelitian ini adalah seperti yang ditunjukan pada gambar 4.

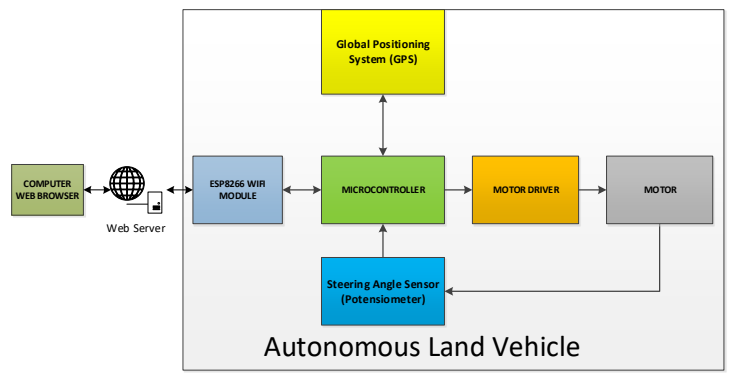

Gbr. 4 Blok diagram Sistem Kendali Wahana

Pada gambar 4 dapat dilihat interkoneksi antar komponen satu dengan komponen lainnya, Sistem ALV ini akan bergerak sesuai dengan lintasan yang diberikan oleh komputer melalui protokol Internet pada Web Control Station, kemudian mikrokontroller akan menerima data dan mengirimkan ke microcontroler sebagai kontroler utama dan disimpan kedalam memory EEPROM sebagai lintasan referensi. GPS bekerja secara kontinyu dan akan mengirimkan data latitude dan longitude hanya ketika mendapatkan sinyal 2 atau 3 satelit, namun dalam penelitian ini, data gps hanya akan diolah jika sudah mendapat minimal 5 buah satelit. Hal ini bertujuan agar informasi yang diberikan oleh GPS memiliki akurasi yang lebih tinggi dibandingkan hanya dengan 3 buah satelit.

Untuk memperoleh kecepatan posisi wahana, digunakan sensor kecepatan motor yaitu encoder. Encoder akan menginformasikan kecepatan putaran motor ke microcontroller sehingga Persamaan (3. 4) dapat dihitung. Suplay daya yang digunakan adalah aki 612 Volt DC, Pengisian daya dapat dilakukan dengan dua cara yaitu dengan menggunakan charger aki dan juga sel surya yang terpasang pada sekeliling permukaan luar wahana.

\section{HASIL DAN PEMBAHASAN}

Dari pengujian penelitian yang telah dilakukan dengan cara memberikan titik-titik yang harus dituju oleh wahana ditujukan pada gambar 5, 6 dan 7.

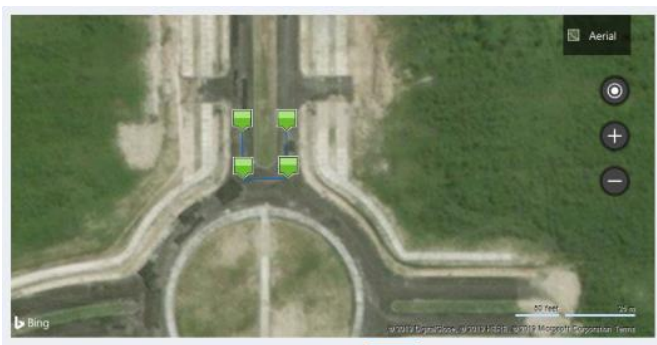

Gbr.5 Waypoint yang harus dilalui wahana

Pada gambar 5 dapat dilihat waypoint yang telah ditentukan oleh pengguna melalui ground control station (GCS). Pada GCS yang berbasis web, digunakan fitur bing map untuk memetakan pergerakan wahana ke dalam map. Dari hasil yang telah diperoleh ditunjukan pada gambar 6 dan 7 .

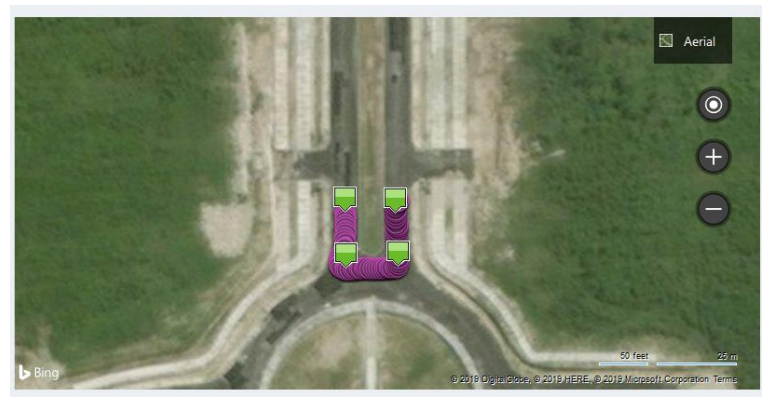

Gbr. 6 Wahana Menjejaki waypoint yang telah ditentukan dipantau dengan GCS

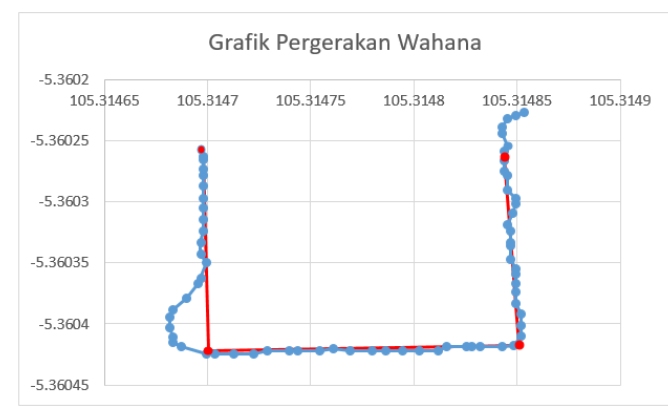

Gbr.6 Grafik Penjejakan dalam koordinat 2 dimensi 
Pada gambar 6 dan 7 dapat dilihat pergerakan wahana yang menuju waypoint yang telah ditentukan pada gambar 5. Hasil pengujian pada gambar 6 menunjukan pemetaan dua dimensi, sedangkan pada gambar 7 menunjukan grafik pergerakan wahana. Dari grafik pada gambar 7 dapat dilihat, wahana mampu mengikuti waypoint yang diberikan dengan baik, yang ditunjukan wahana bergerak tidak terlalu jauh keluar dari trayektori garis lurus yang seharusnya dilalui oleh wahana. Namun ketika wahana berubah dari waypoint 3 menuju waypoint 4 . Wahana mengalami pergerakan belok kanan yang tidak sempurna, hasil pemeriksaan ditemukan kendala yaitu pembacaan sudut potensiometer yang tidak presisi. Sebagai solusi maka perlu digunakan motor servo ukuran besar atau motor stepper sebagai motor steering nya.

\section{KESIMPULAN}

Dari analisis hasil pengujian yang telah dilakukan, maka dapat diperoleh kesimpulan sebagai berikut :

1. Wahana dapat mengikuti waypoint dengan menggunakan sistem kendali PID dan Model Kinematika

2. Pergerakan wahana masih berosilasi, hal ini dikarenakan oleh sensor sudut steering yang tidak presisi

3. Web Ground Control Station berbasis IoT sudah dapat digunakan untuk memonitoring wahana.

\section{ACKNOWLEDGMENTS}

Thanks to Institut Teknologi Sumatera (ITERA), this research is funded by ITERA Smart Mandiri Research.

\section{REFERENSI}

[1] S. Xie and W. Gong, "Fuzzy immune PID control of $\mathrm{pH}$ value in chemical industry process" in 2011 IEEE International Conference on Computer Science and Automation Engineering. Shanghai, China. 2011

[2] G. Jithu and P.R Jayasree, "Quadrotor modelling and control" in 2016 International Conference on Electrical, Electronics, and Optimization Techniques (ICEEOT). Chennai, India. 2016.

[3] G. Petit and C. Thomas " GPS frequency transfer using carrier phase measurements" in Proceedings of 1996 IEEE International Frequency Control Symposium, Honolulu, HI, USA, USA, 1996.

[4] M. Zogg, "Global Positioning System, Standard Positioning System Service, Signal Specification, 2nd Edition," 1995.

[5] S. Mohd, J. Kamal, M Anulhaq And M Shashi " Development and implementation of NMEA interpreter for real time GPS data logging" 2013 3rd IEEE International Advance Computing Conference (IACC), 2013. 